\title{
Surgical Neuroangiography of Intracranial Vascular Malformations
}

\author{
K.G. Ter Brugge, P. Lasjaunias and M.C. Chiu
}

\begin{abstract}
In the three year period of 1982 to 1985,152 patients with intracranial vascular malformations were referred to the Bicetre Hospital in Paris, France and the Toronto Western Hospital in Canada. Sixty-six patients with cerebral vascular malformations and 48 patients with dural vascular malformations underwent endovascular treatment. In 8 patients surgery was performed in combination with the embolization procedure. Detailed analysis of the angio-architecture of the vascular malformation reveals certain characteristics which may be of value in predicting the clinical outcome. Comprehensive data analysis and long term follow-up is necessary to assess the role of embolization in the treatment of intracranial vascular malformations.
\end{abstract}

RÉSUMÉ: Neuroangiographie chirurgicale des malformations vasculaires intracrâniennes Pendant une période de trois ans, soit de 1982 à 1985,152 patients porteurs de malformations vasculaires intracrâniennes ont été référés à l'Hôpital Bicêtre de Paris, France et au "Toronto Western Hospital" de Toronto, Canada. Soixante-six patients porteurs de malformations vasculaires au niveau de la dure-mère ont subi un traitement endovasculaire. Chez 8 patients, on a eu recours à la chirurgie associée à l'embolisation. Une étude détaillée de l'architecture des vaisseaux constituant ces malformations révèle certaines caractéristiques qui peuvent être utiles pour prédire le résultat clinique. Une analyse de l'ensemble des données et un suivi à long terme sont nécessaires pour évaluer le rôle de l'embolisation dans le traitement des malformations vasculaires intracrâniennes.

Can. J. Neurol. Sci. 1987; 14:70-74

The treatment of cerebral vascular malformations has become multi-disciplinary. In addition to surgery, radiation therapy and embolization have become accepted treatment methods over the past 5 years. ${ }^{1,2,3,4,5,6,7}$ Supraselective angiography of intracranial vascular malformations has added significant information with regard to the nidus architecture and associated anomalies. ${ }^{8}$ The results of endovascular treatment of 114 patients with intracranial vascular malformations treatec in the past three years at the Bicetre Hospital in Paris and in the past eighteen months at the Toronto Western Hospital were reviewed.

Special attention was directed towards analysis of the angioarchitecture of the nidus of the lesions, as well as to the venous outflow characteristics and whenever possible these were correlated with the clinical symptomatology.

\section{Materials ANd MethodS}

One hundred and fifty-two patients were referred to the authors for consultation and possible treatment of intracranial vascular malformations ( 125 to Bicetre Hospital and 27 to Toronto Western Hospital).

A detailed record was kept for each patient, including clinical information, previous treatments, topographic information by means of CT and MRI scans, angiographic analysis of feeding vessels, nidus architecture and venous drainage characteristics as well as associated arterial and venous anomalies.

Thirty-eight patients with cerebral arteriovenous malformations (AVM) were not accepted for endovascular treatment because their angiographic characteristics were, in the opinion of the authors, felt to be unfavourable for embolization therapy. Patients with vascular malformations which were supplied by multiple normal or small sized vessels and associated with slow or only slightly increased flow, and in whom there was no history of previous hemorrhage, were not accepted for treatment. All of the patients with dural vascular malformations (D-AVM) were accepted for treatment.

Embolic agents used for treatment varied according to the specific clinical situation. For the treatment of dural arteriovenous malformations a combination of small sized particles (PVA, 160-250 microns) and liquid tissue adhesive (Isobutyl-2-cyanoacrylate, IBCA) was usually used, while for the treatment of cerebral AVM's invariably tissue adhesive was used.

Follow-up angiography and CT scans were obtained on all patients immediately following the embolization procedure and at a one year interval or whenever the clinical situation indicated.

From the Department of Radiology, Toronto Western Hospital, University of Toronto. Canada (Drs. Ter Brugge. Lasjaunias and Chiu) and the Department of Radiology, Bicetre Hospital, Paris, France (Dr. Lasjaunias)

Request reprints to: K. Ter Brugge, Department of Radiology. Toronto Western Hospital, 399 Bathurst St., Toronto, Ontario, Canada M5T 2S8 


\section{RESULTS}

\section{Brain AVM's}

Of the 104 patients referred for consultation, 66 patients with brain AVM's were treated by embolization in 128 sessions. The presenting symptoms were hemorrhage in 25 patients, seizures only in 21 patients, and a combination of progressive neurological deficit, seizures and headaches in 20 patients. The location of the brain AVM's was pure cortical in 31 patients, corticalventricular in 25 patients, basal ganglia and thalamus in four patients, posterior fossa in three patients, and three patients had a vein of Galen ectasia.

The presenting clinical symptoms improved following embolization in 35 patients. Follow-up angiograms demonstrated $75 \%$ obliteration of the lesion in 24 patients (Figure 1) and $100 \%$ obliteration in eight patients (Figure 2). In 13 patients a complication occurred related to the endovascular treatment. A transient neurological deficit occurred in nine patients (13.5\%) and a permanent deficit occurred in three patients $(4.5 \%)$. One patient died following inadvertent inflation of the calibrated

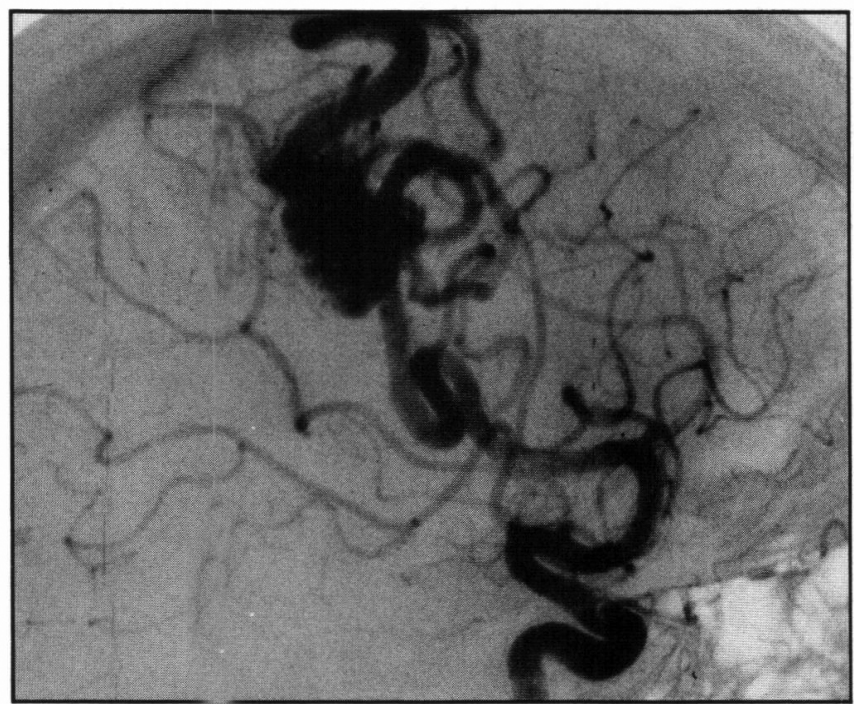

A

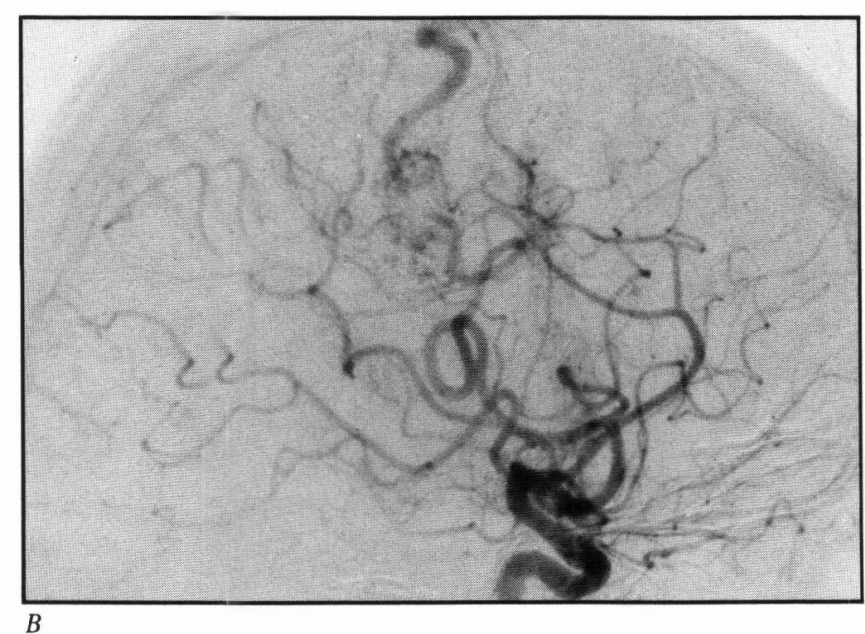

Figure I-Brain AVM, partially embolized. A 29-year-old female with longstanding history of seizures. A) Internal carotid angiogram, lateral view, prior to embolization. B) Six months after embolization. About $80 \%$ obliteration of the lesion is noted. No complications were apparent. Seizure activity diminished slightly following endovascular treatment.

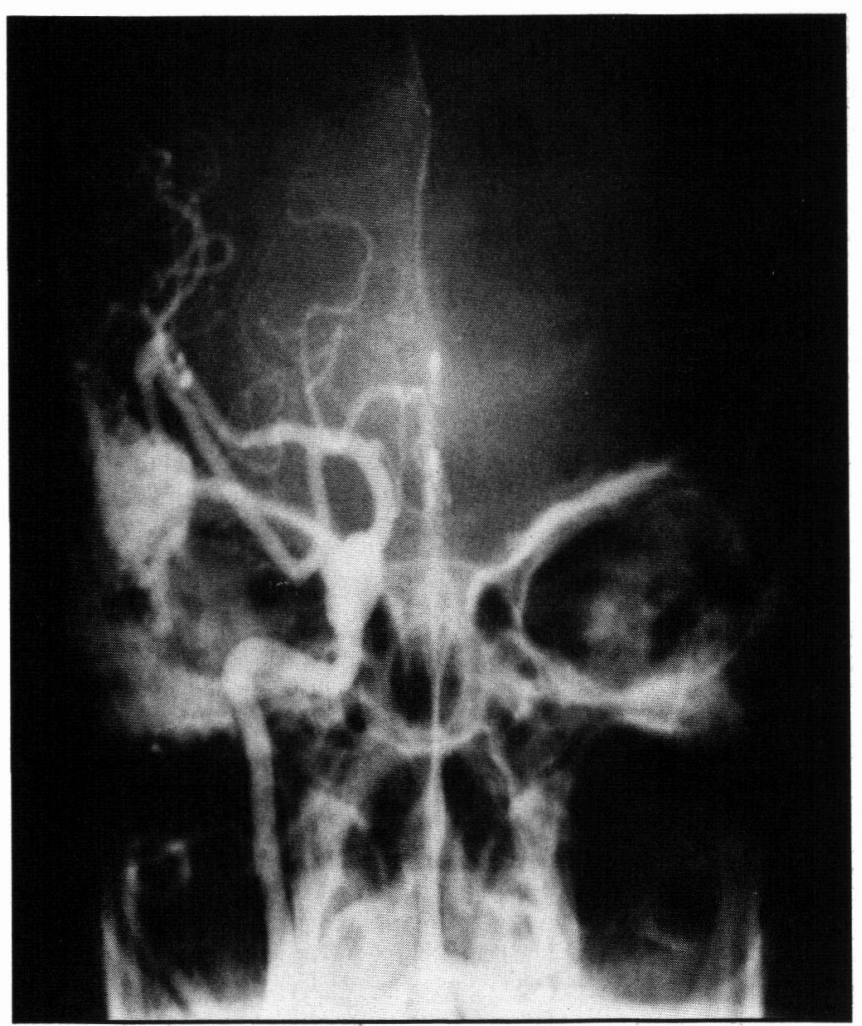

A

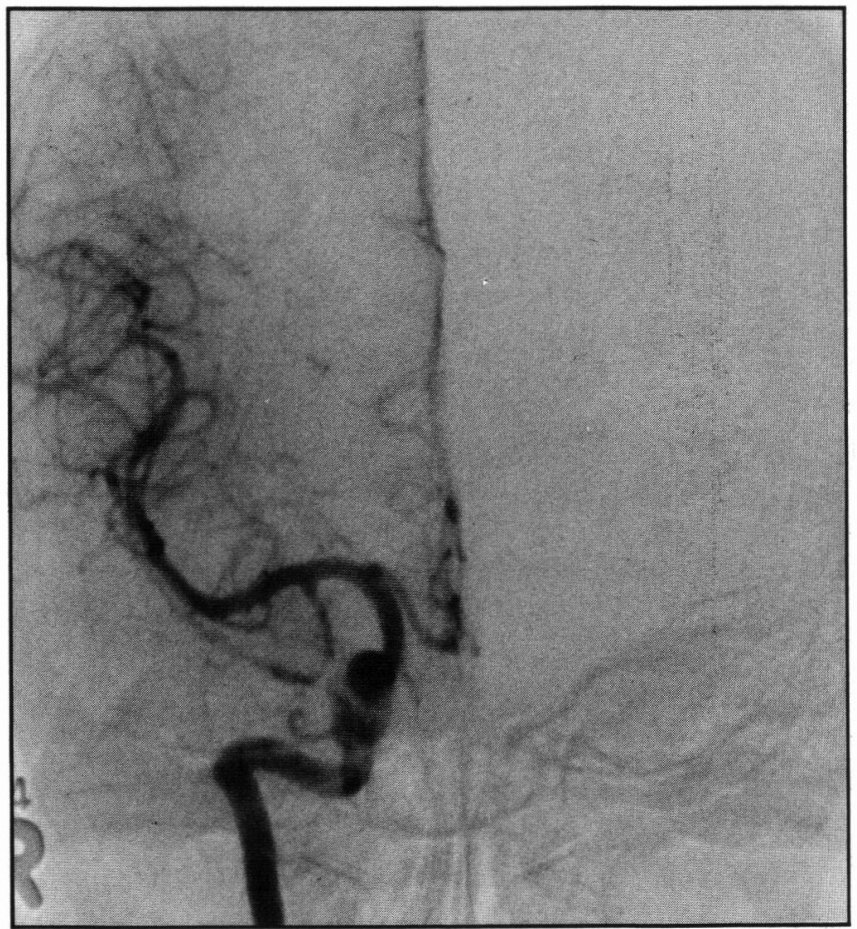

$B$

Figure 2-Brain AVM, comletely embolized. A 59-year-old female with longstanding history of temporal lobe seizures. A) Common carotid angiogram, frontal view, (outside film) prior to embolization. B) Internal carotid angiogram, frontal view, one year after embolization. Complete obliteration of the temporal lobe AVM is noted. No complications were apparent. Seizure activity decreased significantly following endovascular treatment. 
leak balloon in a normal perforating branch of the basilar artery which lead to rupture of this vessel with hemorrhage and death.

Six patients underwent surgery following the embolization procedure, with resultant partial removal of the AVM in two patients and complete removal in four patients. In a three year follow-up, rebleeding occurred in two patients, in whom the embolization had incompletely obliterated the AVM.

\section{Dural AVM's}

All of the 48 patients who were referred for consultation were accepted for treatment. The location of the lesion was anterior cranial fossa in one patient, orbit in one, sphenoid wing in two, parasellar in 18, tentorial in five, lateral sinus and torcular in 19 and foramen magnum in two. Cortical venous drainage was noted in 20 patients. The clinical presentation of dural vascular malformations was recently reviewed by the authors. ${ }^{9} \mathrm{Com}$ plete obliteration of the AVM as determined by angiography was achieved in 16 patients. Symptoms were relieved following embolization in 44 patients. A transient neurological deficit (cranial nerve palsy) occurred in two patients (4\%) but no permanent deficit occurred. In three patients endovascular treatment was supplemented by surgery in order to achieve complete obliteration of the lesion.

\section{DISCUSSION}

"Surgical neuroangiography" or interventional neuroradiology has become a full time specialty in a few centres in France. Their experience is gradually expanding and several centres have emerged in North America. With the collaboration of one of the authors (P.L.) a centre for surgical neuroangiographic techniques has been established at Toronto Western Hospital. Referred patients are carefully analyzed according to an extensive vascular malformation protocol. Detailed analysis of the angio architecture of both dural and cerebral AVM's has led to several important observations.

Analysis of the patients with dural AVM's has shown that the presence of cortical venous drainage (Figure 3) represents an absolute indication for aggressive treatment. ${ }^{9}$ These lesions tend to occur along the floor of the anterior cranial fossa as well as the tentorium, and frequently present with intracerebral, subarachnoid or subdural hemorrhage. Therefore these lesions must be completely eliminated, either by embolization alone or in combination with surgery. Treatment of dural AVM's without cortical venous drainage can be made much less aggressive, and should be based on disability caused by the clinical symptoms and natural history of the lesion balanced against the risks of treatment.

The topography of brain AVM's is usually well shown by means of MRI and CT scans. ${ }^{10.11}$ High quality selective angiography is required to make therapeutic decisions. Note should be made of associated arterial anomalies such as aneurysms and ectasias; the nidus architecture such as a vascular network, arteriovenous shunt, intralesional aneurysms or venous ectasias, as well as the venous outflow characteristics of the vascular malformation should be carefully studied.

Aneurysms associated with brain AVM's that are not arising from the parent vessel feeding the AVM should probably be treated by surgery prior to embolization of the AVM. ${ }^{12}$ Intralesional aneurysms need to be treated at the same time as the AVM and therefore deposition of embolic material in the nidus should include the intralesional aneurysm. Aneurysms arising from the feeding artery proximal to the AVM often regress in size following the treatment of the AVM. (Figure 4$)^{12}$

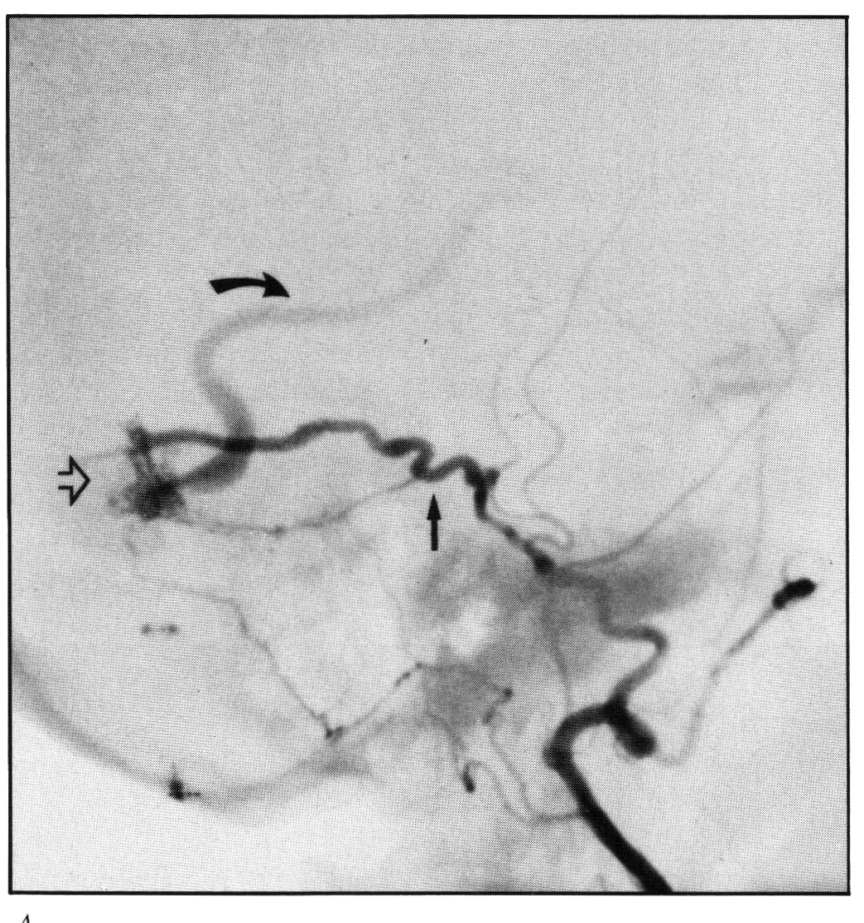

A

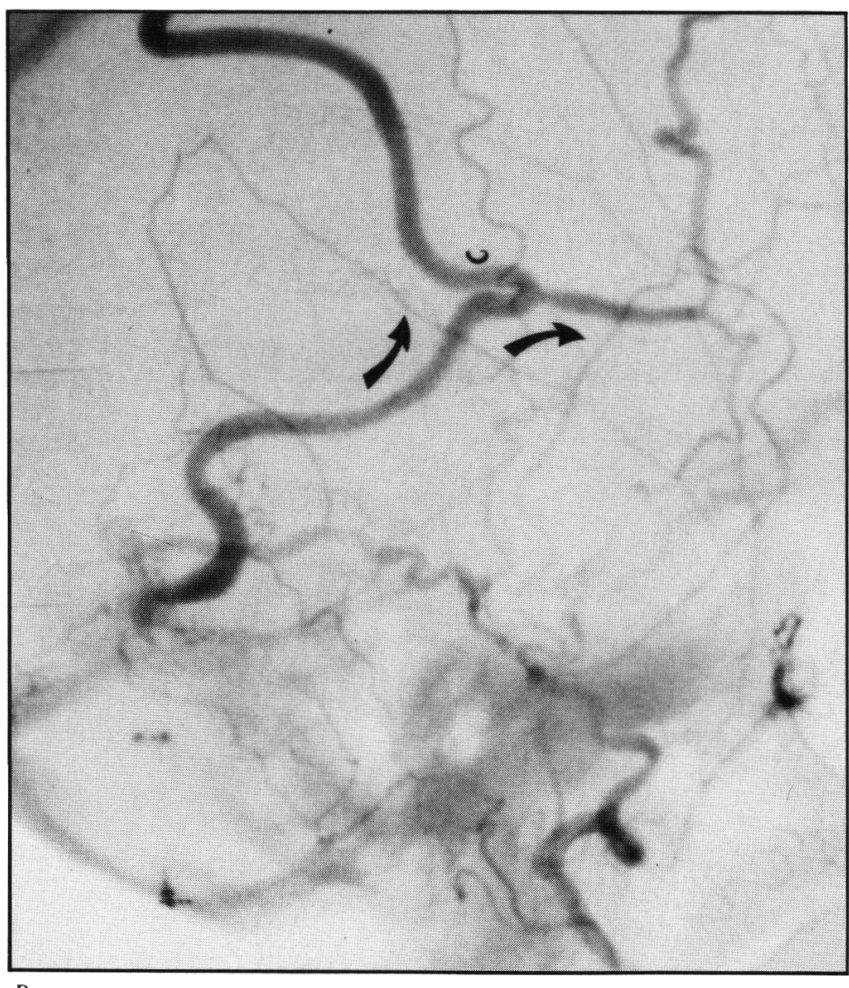

$B$

Figure 3-Dural AVM with cortical venous drainage. 53-year-old female with temporal lobe seizures and a bruit. A) Distal external carotid angiogram, lateral view, early arterial phase. B) Late phase. The nidus of the dural AVM (open arrow) is seen adjacent to the transverse simus and is fed mainly by the petrosquamosal branch of the middle meningeal artery (arrow) and drains towards the cortical venous system of the brain. (curved arrows) 
Dural AVM's with cortical venous drainage may present with clinical symptoms similar to brain AVM's. Since the feeding arteries and the nidus are obviously in different anatomical locations, the only common feature between these conditions is their venous drainage characteristics.

It therefore appears reasonable to suspect that the clinical symptoms of brain AVM's may be related to the influence of their venous drainage characteristics.

Venous outflow anomalies in patients with vein of Galen ectasia have been recently reviewed by the authors ${ }^{13}$ and appear to indicate a strong relationship between the clinical symptoms and the site of venous obstruction. The presence of intralesional venous pouches or venous kinking (Figure 5), may represent an increased risk for hemorrhage, and only long term follow-up will determine whether the disappearance of these venous anomalies following partial embolization will result in decreased risk of hemorrhage. (Figure 6)

The Paris-Toronto experience is unique in that it consists of a large number of patients treated by embolization alone. It will therefore represent a valuable series for comparison with other

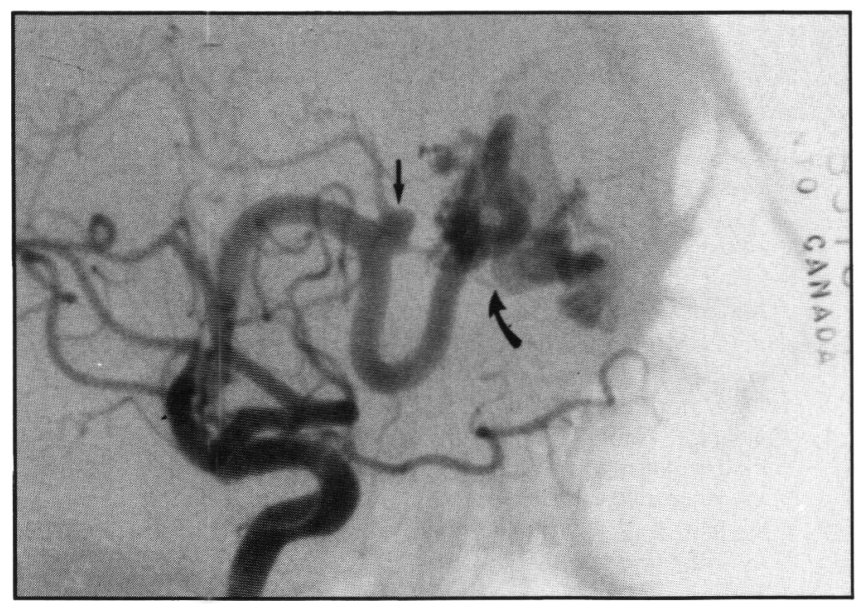

A

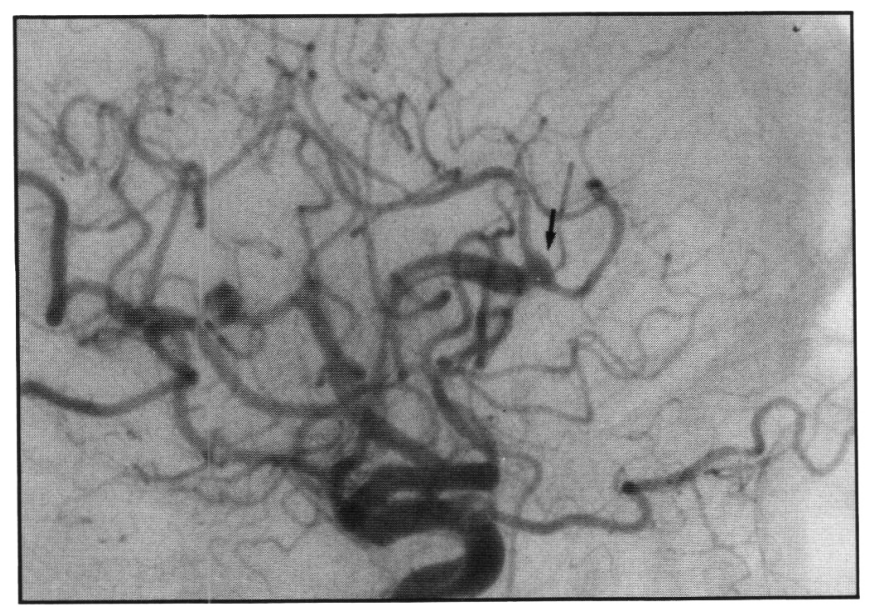

$B$

Figure 4-Brain AVM with aneurysm. A 43-year-old male presented with longstanding history of seizures which had become refractory to medical treatment. A) Internal carotid angiogram, lateral view, prior to embolization. $B$ ) Three months after embolization regression of the aneurysm (arrow) is noted on the parent vessel after embolization of the frontal lobe AVM (curved arrow). No complications were noted. Seizure activity dimished following endovascular treatment. treatments such as surgery alone or in combination with embolization and/or radiation.

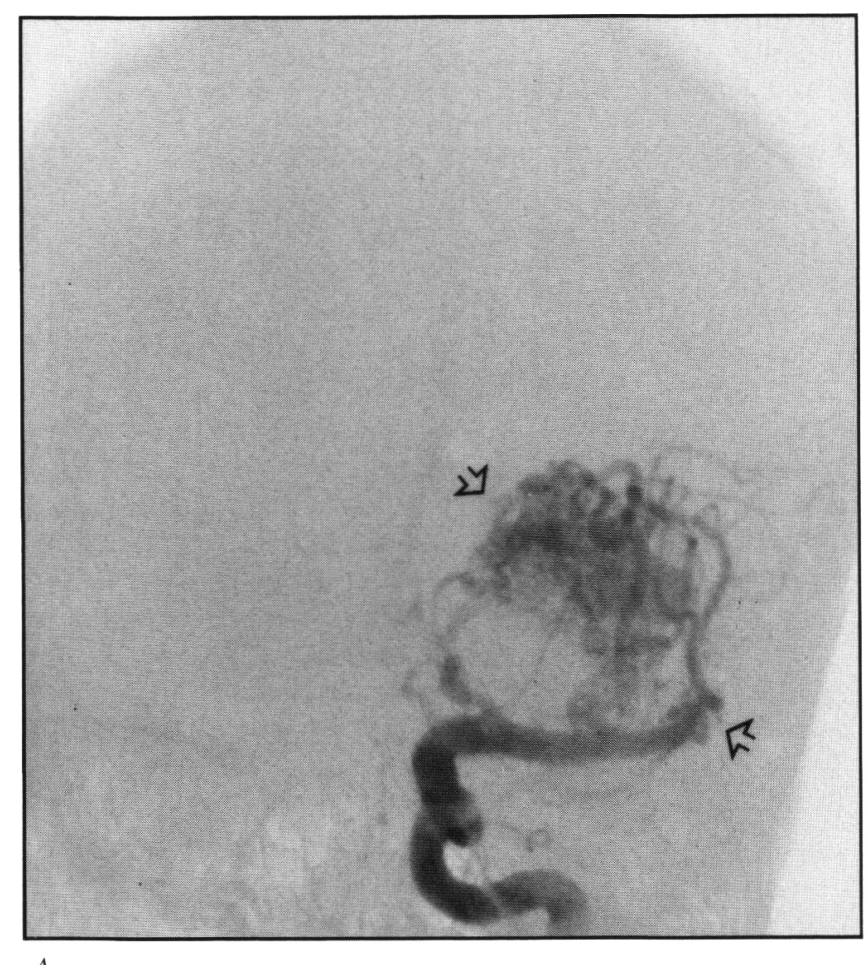

A

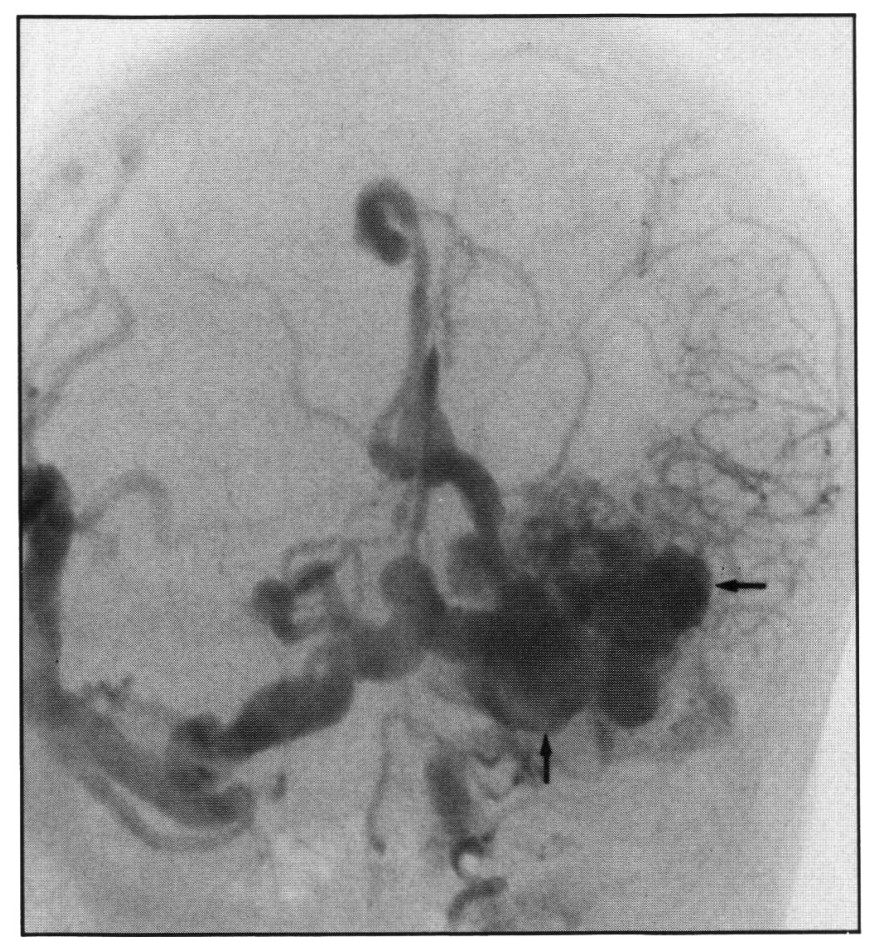

$B$

Figure 5 - Brain AVM withintralesionalvenous pouches. 64-year-old female with three previous episodes of intracerebral hemorrhage which resulted in a permanent neurological deficit. A) Internal carotid angiogram. frontal view, early phase. B) Late phase, show's a deep seated AVM. The $A V M$ is fed by multiple branches of the middle cerebral artery (open arrows) prominent intralesional venous pouches (arrow's) are noted as well as venous drainage towards the opposite side and to the ipsilateral deep venous drainage system. 
The present review of intracranial AVM's is preliminary. The ten years experience with supraselective angriography at the Bicetre Hospital in Paris and the 18 month experience at the Toronto Western Hospital strongly suggest that detailed analysis of high quality subtraction magnification angiograms will

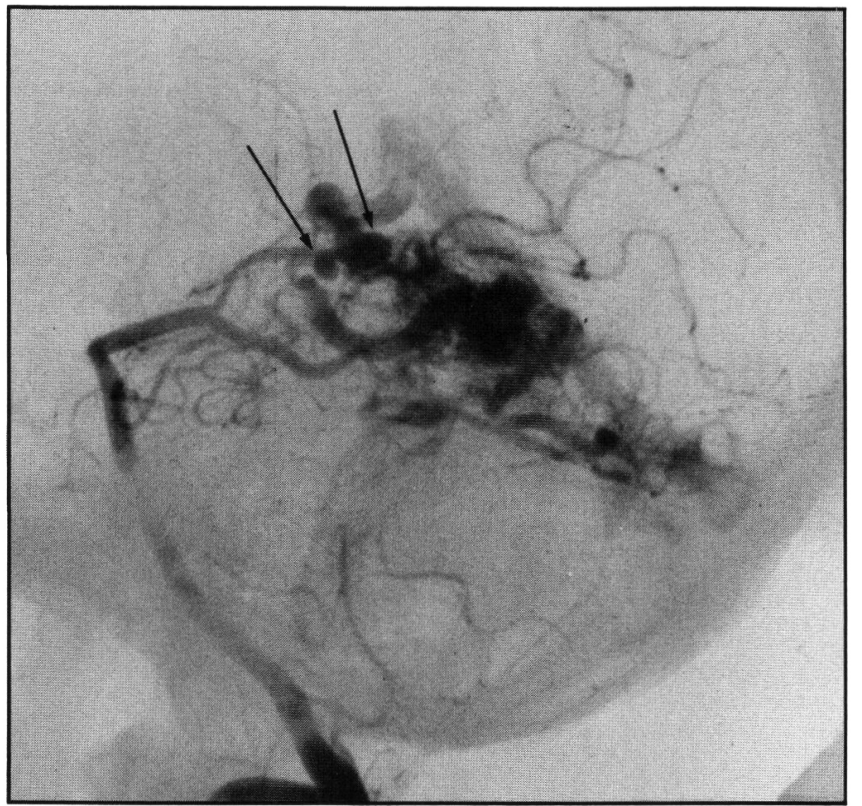

A

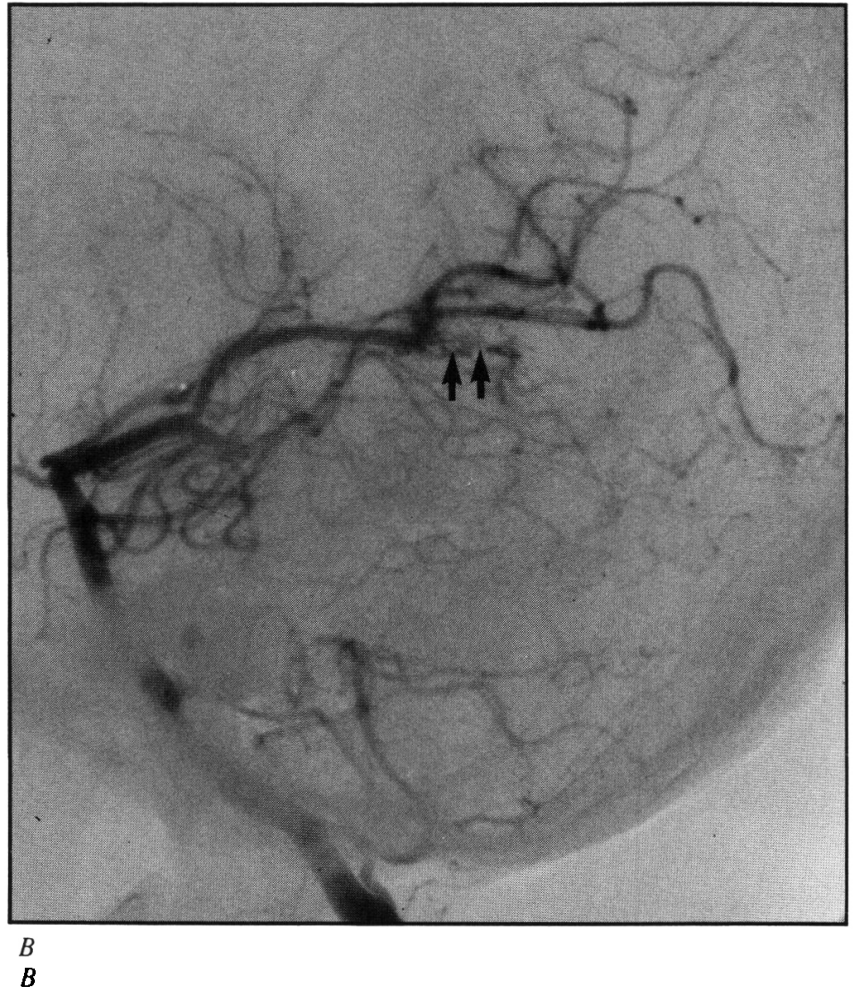

Figure 6-Brain AVM with venous kinking. A 23-year-old male with a history of recent onset of seizures. A) Vertebral angiogram, lateral view. prior to embolization. B) Immediately following embolization. Venous kinking (long arrows) is noted along the tentorial edge prior to embolization of this occipital lobe AVM. This appearance was no longer demonstrated following incomplete obliteration of the AVM. Minute residual nidus is noted (small arrows). No complications were apparent and no change in the clinical symptoms occurred. lead to a better understanding of the pathophysiological basis of the symptoms and natural history, and should lead to improved treatment.

Long term follow-up will be necessary to accurately determine the results of endovascular treatment especially in patients in whom the lesion has been only partially obliterated. Early indications are that endovascular treatment, if performed by experienced teams, represents a relatively safe and effective treatment, to be seriously considered either alone or in combination with surgery in the treatment strategy of patients with intracranial AVM's.

\section{ACKNOWLEDGMENTS}

The authors wish to acknowledge our neurological and neurosurgical colleagues for referring their patients to us for consultation and endovascular treatment. In particular we would like to thank our neurosurgical colleagues at Toronto Western Hospital - (Doctors Tator, Schutz, Fleming, Vanderlinden and Bernstein), at the Sunnybrook Medical Centre - (Doctors Rowed and Schwartz), at the Wellesley Hospital - (Doctors Bruni and Smyth), at the Hospital for Sick Children - (Doctors Hoffman and Humphreys), and Doctor Duherty of the British Columbia Children's Hospital.

\section{REFERENCES}

1. Debrun G, Vinuela F, Fox A et al. Embolization of cerebral arteriovenous malformation with bucrylate. Experience in 46 cases. $J$. Neurosurg 1982, 56: 615-627.

2. Kjellberg RN, Hanamura $\mathrm{T}$, David $\mathrm{K}$ et al. Bragg Peak proton beam therapy for arteriovenous malformations of the brain: New Eng J Med 1983, 309: 269-274.

3. Picard L, Moret J, Lepoive J. Endovascular treatment of intracerebral arteriovenous angiomas. Technique, indications and results. J Neuroradiology 1984, 11: 9-28.

4. Vinuela FV, Debrun GM, Fox AJ. Dominant-hemisphere arterivenous malformations: therapeutic embolization with isobutyl-2-cyanoacrylate. Amer J Neuroradiology, 1983, 4: 959-966.

5. Vinuela F, Fox AJ. Interventional neuroradiology and the management of arteriovenous malformations and fistulae. Neuro Clin 1983, 1: 131-153.

6. Vinuela FV, Fox AJ, Debrun G. Progressive thrombosis of brain arteriovenous malformations after embolization with isobutyl2-cyanoacrylate. Amer J Neuroradiology, 1983, 4: 1233-1238.

7. Vinuela F, Fox AJ, Debrun G. Pre-embolization superselective angiography: Role in the treatment of brain arteriovenous malformations with Isobutyl-2-Cyanoacrylate. Amer J Neuroradiology, 1984, 5: 765-769.

8. Lasjaunias P, Manelfe C, Chiu M. Angiographic architecture of Intracranial arteriovenous malformations and fistulas: Neurosurgical Review, 1986, in press.

9. Lasjaunias P, Chiu M, Ter Brugge K, et al. Neurological manifestations of intracranial dural arteriovenous malformations. $J$ Neurosurg 1986, 64: 724-730.

10. Kucharczyk W, Lemme-Pleghos $\mathrm{L}$, et al. Intracranial vascular malformations MR and CT imaging: Radiology. 1985, 156: 383-389.

11. Ter Brugge K, Scotti G, Ethier R, et al. Computer tomography and intracranial arteriovenous malformations. Radiology, 1977, 122: 703-705.

12. Takara $\mathrm{E}$, Inoue $\mathrm{N}$, Kohno $\mathrm{H}$. [Disappearance of the co-existing aneurysm and arteriovenous malformation after wrapping of aneurysm.] No Shinkei Geka, 1980, 8: 587-591, (Jpn).

13. Lasjaunias $P$, Ter Brugge $K$, Lopas $L$. The role of dural anomalies in the vein of Galen aneurysms: Amer J Neuroradiology, 1987, accepted for publication. 